\title{
Cold water immersion of the ankle decreases neuromuscular response of lower limb after inversion movement
}

\author{
Christiane S. G. Macedo ${ }^{1}$, Carolina S. Alonso ${ }^{1}$, Rogério F. Liporaci ${ }^{2}$, \\ Fernando Vieira ${ }^{2}$, Rinaldo R. J. Guirro ${ }^{1}$
}

\begin{abstract}
Background: Cryotherapy has been associated with a significant decrease in nerve conduction velocity and muscle contraction with possible effects on exercise and physical training. Objectives: To quantify the electromyographic response of the lateral gastrocnemius, tibialis anterior, fibularis longus, rectus femoris and gluteus medius to ankle inversion following cold water immersion. Method: The peak values of the root mean square (RMS) were obtained from 35 healthy and active university subjects after the use of a tilt platform to force the ankle into $30^{\circ}$ of inversion before, immediately after, and 10, 20, and 30 minutes after water immersion at $4 \pm 2^{\circ} \mathrm{C}$, for 20 minutes. The Shapiro-Wilk test, repeated measures analysis, Bonferroni's post-hoc, and linear regression analysis provided the results. Results: Peak RMS was significantly lower at all times after cold water immersion, with residual effect of up to 30 minutes, when compared to pre-immersion for all muscles, except for immediate post-immersion for the gluteus medius. Conclusions: After cold water immersion of the ankle, special care should be taken in activities that require greater neuromuscular control.
\end{abstract}

Keywords: cryotherapy; electromyography; inversion platform; ankle; physical therapy.

ClinicalTrials.gov Identifier: NCT01870414

\section{HOW TO CITE THIS ARTICLE}

Macedo CSG, Alonso CS, Liporaci RF, Vieira F, Guirro RRJ. Cold water immersion of the ankle decreases neuromuscular response of lower limb after inversion movement. Braz J Phys Ther. 2014 Jan-Feb; 18(1):93-97. http://dx.doi.org/10.1590/ S1413-35552012005000132

\section{Introduction}

Cryotherapy is indicated in the management of acute tissue injuries ${ }^{1}$. Its effectiveness is well established in pain relief, edema and inflammatory process control, and decreases in blood flow, metabolic rate, temperature, and intramuscular nerve conduction velocity ${ }^{2}$. In clinical practice, it is used in sports injuries of the ankle/foot and in injuries of physically active individuals during physical therapy ${ }^{3}$.

Bleakley and Costello ${ }^{2}$ pointed out that the application of topical cooling prior to exercise has become a popular method; however, the authors report that its benefits should compensate any deleterious physiological effects, considering that it has been associated with a significant decrease in nerve conduction velocity ${ }^{4,5}$ in muscle contraction ${ }^{6}$ and with possible effects on exercise and physical training ${ }^{7}$.

Currently, studies ${ }^{8-10}$ have shown different results related to the effects of local cooling on proprioception $^{11}$, motor control ${ }^{12}$, joint position ${ }^{3,9}$, and electromyographic (EMG) response ${ }^{13}$. Despite the frequent use of cryotherapy in the final stages of rehabilitation for foot and ankle injuries in athletes and the early return to sport, there is disagreement about the effect of cooling on peroneal muscle function during weight-bearing exercise ${ }^{13}$ and on other muscles related to this joint and the lower limbs. It is assumed that, with the decrease in nerve conduction velocity and consequently less recruitment and muscle activity, the ankle is left vulnerable to injury. However, there is limited evidence on the effects of local cooling on motor control ${ }^{8,10}$, which reinforces the need for further studies on the subject.

Therefore, the present study aimed to determine the effect of cold water immersion of the ankle on the amplitude of the EMG response of the corresponding lower limb muscles after ankle inversion, as well as to detect the possible changes 30 minutes post-immersion.

\footnotetext{
${ }^{1}$ Department of Biomechanics, Medicine and Rehabilitation, Ribeirão Preto Medical School, Universidade de São Paulo (USP), 


\section{Method}

This study uses an analysis of repeated measures design to determine the peak RMS (Root Mean Square) values of the lateral gastrocnemius (LG), tibialis anterior (TA), fibularis longus (FL), rectus femoris (RF), and gluteus medius (GM) muscles, before (pre), immediately after (post), and 10, 20, and 30 minutes after cold water immersion.

The study was approved by the Research Ethics Committee of Hospital das Clínicas, Faculdade de Medicina de Ribeirão Preto/Universidade de São Paulo (FMRP/USP), Ribeirão Preto, SP, Brazil protocol number 2968/2010, and all volunteers signed an informed consent form. The study was registered as a clinical trial (ClinicalTrials.gov Identifier: NCT01870414) and met the ethical standards in sport and exercise science research ${ }^{14}$.

The volunteers were recruited by verbal invitation on the university campus and referred to evaluation and screening. The exclusion criteria were as follows: history of muscular or joint injury to the lower limbs in the last six months; diagnosis of metabolic, rheumatic or balance disorders; and cold or pain hypersensitivity during the tests.

A convenience sample of 39 participants fulfilled the required criteria; however, 4 were excluded due to incompatible schedules. Our main focus was to evaluate healthy subjects for the integrity of the sensory and motor system, thus determining the results obtained exclusively from cold water immersion applied to the cooled and non-cooled lower limb muscles.

For the EMG signals, the Myomonitor IV (Delsys, Boston, MA, USA) was used. This module has impedance of $10^{9} \mathrm{Ohms}$, 16-bit resolution, input band of $1 \mathrm{~V}$, sampling frequency of $1000 \mathrm{~Hz}$, bandpass filters of 20 to $450 \mathrm{~Hz}$, Overall Channel Noise $\leq 1.2 \mathrm{uV}$
RMS, with microcomputer connection and 1000x gain. The single differential surface sensors (Delsys, Boston, MA, USA) had 1-mm wide x 10-mm long silver-bar electrodes, $10 \mathrm{~mm}$ apart, Preamplifier Gain $10 \mathrm{~V} / \mathrm{V} \pm 1 \%$, CMRR - $92 \mathrm{~dB}$, and Input Impedance $>10^{15} \Omega / / 0.2 \mathrm{pF}$. Data Acquisition Software was used (Delsys, Boston, MA, USA) for acquisition, storage, and analysis of data.

For fixation of the electrodes, the volunteer was asked to stand up. After the skin was shaved and cleansed, the electrodes were fixed over the muscle bellies following the standards of the international protocol, Surface Electromyography for the Non-Invasive Assessment of Muscles. A reference electrode was positioned on the anterior, ipsilateral tibial tuberosity with double-sided adhesive and elastic bandage.

The volunteer was in the orthostatic position on a tilt platform, eyes open and bare feet (Figure 1). The platform was synchronized with the electromyography equipment and activated by the computer. The device specifications and the inversion angle $\left(30^{\circ}\right)$ were based on a systematic review ${ }^{15}$. Each subject received instructions and was given the opportunity to feel the sudden inversion perturbation so this movement could be learned and recognized. The collection consisted of six tilts, three movements for each side, at random. For the data analysis, the mean value of the three collections was considered after the tilt of the platform for the dominant leg (defined as the leg that the subject would choose to kick a ball).

Next, the subjects were placed in a seated position. The dominant leg was immersed for 20 minutes $^{13,16}$ in cold water at a temperature of $4 \pm 2{ }^{\circ} \mathrm{C}^{17}$ and a depth of $20 \mathrm{~cm}$, below the positioning of the electrodes; therefore, there was no need to remove those between trials. The water temperature was controlled using an infrared thermometer (MultTemp ${ }^{\circledR}$, Porto Alegre,
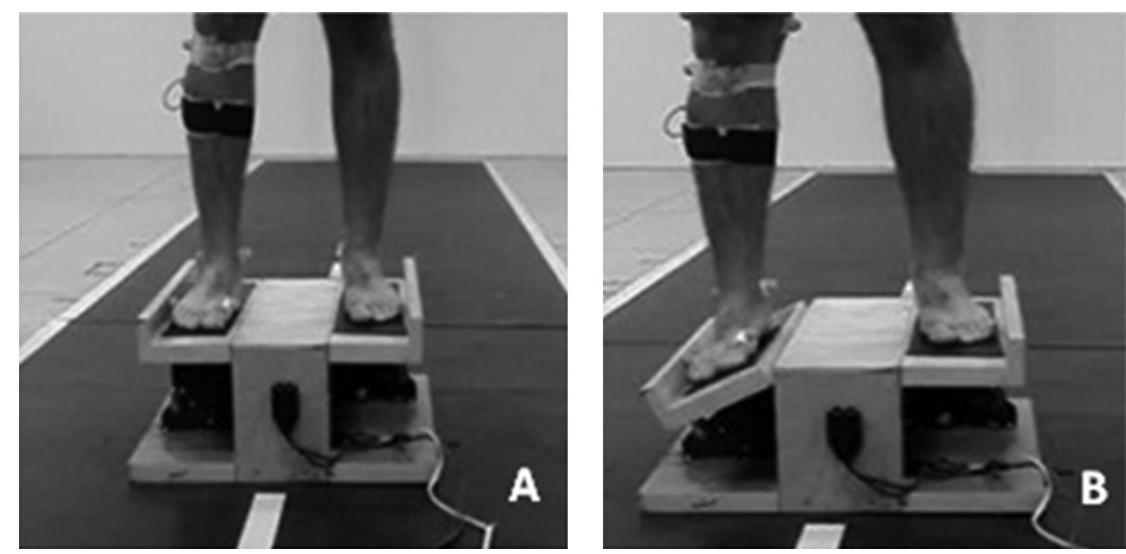

Figure 1. Before (A) and after (B) $30^{\circ}$ of ankle inversion movement, after the tilt of the platform. 
RS, Brazil). The cold water was stirred during the procedure, and whenever necessary, some ice cubes were added to maintain the temperature. After immersion, the lower limb was dried with a towel. The skin surface temperature of the anterior ankle region was measured to confirm cooling.

For the analysis, the peak RMS after the tilt of the inversion platform at $30^{\circ}$ was considered. Similarly, Berg et al. considered that higher levels of RMS showed greater muscle activity ${ }^{13}$. For normalization of the peak RMS signal, pre-cold water immersion was considered as $100 \%$ because it is considered a dynamic activity ${ }^{18,19}$.

Results were verified by applying the ShapiroWilk test, repeated measures analysis, Bonferroni's post-hoc test, and linear regression analysis. The statistical analysis was performed using the Statistical Package for Social Sciences $\left(\mathrm{SPSS}^{\circledR}\right.$ ), version 15.0. The level of statistical significance was set at $5 \%$.

\section{Results}

Thirty-five male subjects, $21.6( \pm 3.2)$ yrs of age, $177.9( \pm 7.9) \mathrm{cm}$ tall, $82.8( \pm 19.3) \mathrm{Kg}$ in weight and $25.9( \pm 4.8) \mathrm{Kg} . \mathrm{m}^{-2}$ of body mass index (BMI), were evaluated. Skin surface temperature before and after cold water immersion was $27.7( \pm 3)^{\circ} \mathrm{C}$ and 7.1 $( \pm 1)^{\circ} \mathrm{C}$, respectively $(\mathrm{p}=0.0001)$.

The results in Table 1 show that the peak RMS values were significantly lower for all postimmersion times when compared to those obtained pre-immersion for all muscles, except for immediate post-immersion for GM.

Linear regression analysis was used to determine the decreasing patterns of the peak RMS values. It was observed that the non-cooled muscles (RF and GM) that were not related morphologically to the ankle/foot responded in a more uniform manner to the cooling over time, justifying the use of this experimental model (Figure 2). In contrast, the three

Table 1. Electromyographic analysis of the peak RMS values of the dominant lower limb muscles after the tilt of the inversion platform at $30^{\circ}$. Mean values (SD) expressed as percentage of pre cold water immersion peak $(\%) . \mathrm{n}=35$.

\begin{tabular}{|c|c|c|c|c|c|}
\hline \multirow[b]{2}{*}{ Muscles } & \multirow[b]{2}{*}{ Pre } & \multicolumn{3}{|c|}{$\begin{array}{l}\text { Moment analysis with } \\
\text { cold water immersion }\end{array}$} & \multirow[b]{2}{*}{$\begin{array}{c}\text { Post } \\
30 \mathrm{~min}\end{array}$} \\
\hline & & Post & $\begin{array}{l}\text { Post } \\
10 \mathrm{~min}\end{array}$ & $\begin{array}{l}\text { Post } \\
20 \mathrm{~min}\end{array}$ & \\
\hline $\begin{array}{l}\text { Lateral } \\
\text { gastrocnemius }\end{array}$ & $\begin{array}{l}100 \\
(0)\end{array}$ & $\begin{array}{l}68.34 * \\
(31.30)\end{array}$ & $\begin{array}{l}69.14 * \\
(30.22)\end{array}$ & $\begin{array}{l}66.26^{*} \\
(29.87)\end{array}$ & $\begin{array}{l}66.62 * \\
(29.83)\end{array}$ \\
\hline Tibialis anterior & $\begin{array}{l}100 \\
(0)\end{array}$ & $\begin{array}{l}53.73^{*} \\
(25.55)\end{array}$ & $\begin{array}{l}55.78^{*} \\
(30.24)\end{array}$ & $\begin{array}{l}63.74 * \\
(50.19)\end{array}$ & $\begin{array}{l}50.19^{*} \\
(29.20)\end{array}$ \\
\hline Fibularis longus & $\begin{array}{l}100 \\
(0)\end{array}$ & $\begin{array}{l}73.65^{*} \\
(43.58)\end{array}$ & $\begin{array}{l}74.91 * \\
(35.03)\end{array}$ & $\begin{array}{l}73.29^{*} \\
(37.84)\end{array}$ & $\begin{array}{l}71.10^{*} \\
(39.21)\end{array}$ \\
\hline Rectus femoris & $\begin{array}{l}100 \\
(0)\end{array}$ & $\begin{array}{l}73.22 * \\
(47.00)\end{array}$ & $\begin{array}{l}62.77 * \\
(32.73)\end{array}$ & $\begin{array}{l}65.28^{*} \\
(36.34)\end{array}$ & $\begin{array}{l}64.78^{*} \\
(49.29)\end{array}$ \\
\hline Gluteus medius & $\begin{array}{l}100 \\
(0)\end{array}$ & $\begin{array}{c}86.21 \\
(31.90)\end{array}$ & $\begin{array}{l}82.67 * \\
(25.02)\end{array}$ & $\begin{array}{l}81.23^{*} \\
(24.05)\end{array}$ & $\begin{array}{l}75.83^{*} \\
(30.43)\end{array}$ \\
\hline
\end{tabular}

Mean values (SD) expressed as percentage of pre cold water immersion peak $(\%)$. * Statistically significant difference when compared to pre cold water immersion time $(\mathrm{p}<0.05)$. Repeated measures analysis and Bonferroni's post-hoc test.

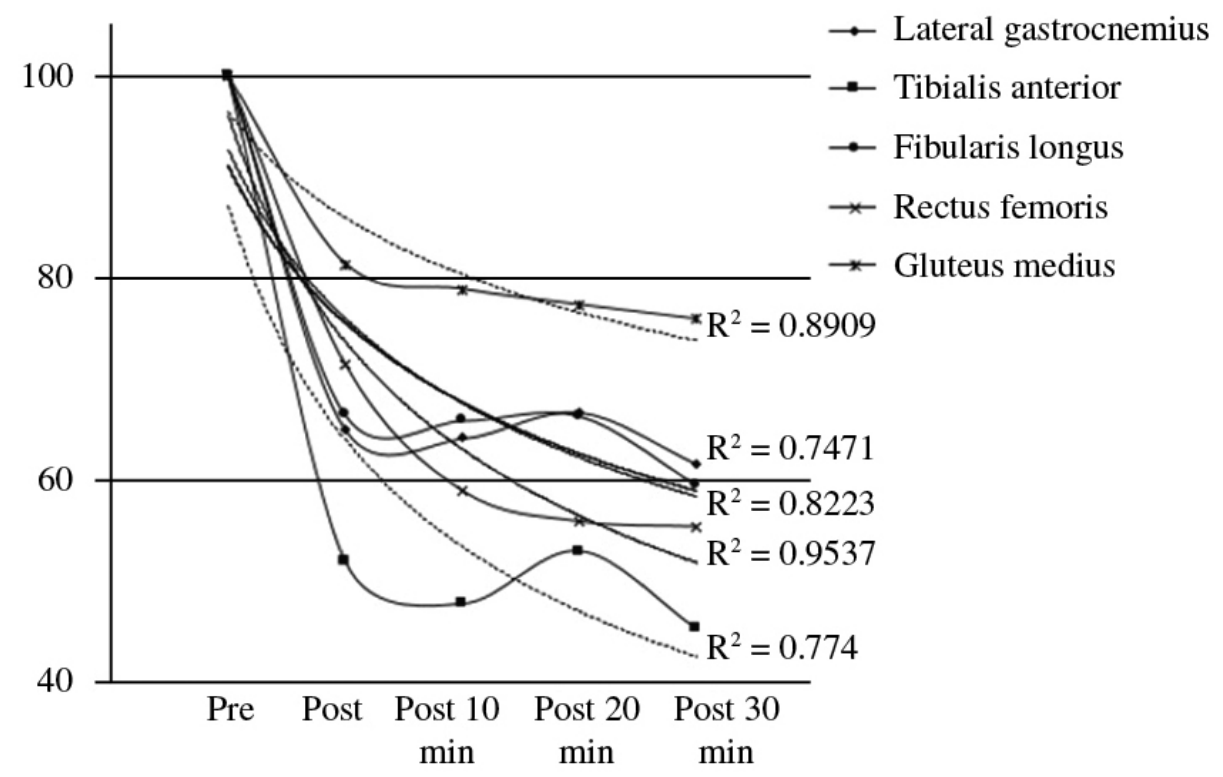

Figure 2. Behavior of the peak RMS values of the dominant lower limb muscles, after the tilt of the inversion platform at $30^{\circ}$ pre and post cold water immersion. Trend line and $R^{2} . n=35$. 
other muscles that act on the ankle joint showed a very similar pattern after the cooling treatment.

\section{Discussion}

Based on the results, cold water immersion for 20 minutes at $4^{\circ} \mathrm{C}$ was effective in reducing skin surface temperature in agreement with Wolf and Basmajian ${ }^{20}$, who reported decreases in skin and intramuscular temperatures after a 5-minute intervention. These results are consistent with Rupp et al. ${ }^{12}$, who concluded that cold water immersion was more effective in significantly decreasing intramuscular temperatures in the gastrocnemius when compared to crushed-ice bag during treatment and 90 minutes post-treatment.

Many studies have used electromyography to analyze ankle muscle response $\mathrm{e}^{10,15}$ and ankle inversion ${ }^{13,21}$. In addition, the present study evaluated the effects of cold water immersion on the electromyographic response of muscles that are not mechanically related to the cooled ankle joint. Thus, our study analyzed the RF and GM muscles, which showed a decrease in RMS immediately after the use of cold water immersion, with residual effect that lasted up to $30 \mathrm{~min}$.

The RF is a powerful knee extensor and the GM stabilizes the lateral movement of the pelvis, hip, and knee. Although the ankle inversion causes an anterolateral joint imbalance, consequently it triggers an ascending force to the pelvis, leading to a decrease in activation of the ankle muscles that can change the muscular responses around the hip and knee. This change could be explained in part by the existing modulation response coming from the skin, joint, and muscle receptors, while a reduction in distal afferents would cause an inhibitory effect of the proximal muscle activity. Thus, the cooling of the ankle had a direct reflection on the muscular activity of the noncooled muscle/joint complexes of the knee and hip.

Following the same pattern, all muscles (LG, TA, and FL) mechanically related to the ankle that received cryotherapy showed significant reduction in RMS. These findings can be explained by the fact that cryotherapy causes a reduction in amplitude and an increase in latency of motor nerve conduction ${ }^{5,22}$, causing changes in the structures of the axon membrane and in the muscle conductivity of sodium and potassium channels, with a reduction in motor nerve conduction ${ }^{22,23}$, mainly of the sensorial nerves ${ }^{5}$. Moreover, Khanmohammadi et al. ${ }^{3}$ suggested a linear relationship between the rate of muscle spindle discharge and reduced muscle temperature, which can be confirmed by our findings. The results of these studies contrast with those of Berg et al. ${ }^{13}$ and Cordova et al. ${ }^{21}$ who observed no differences in FL amplitude or latency during inversion perturbation after cooling the ankle joint. Uchio et al. ${ }^{24}$ reported some concern for the return of athletes to exercise after cryotherapy because the results from different studies are contradictory, justifying the need for further studies.

There are some limitations that need to be acknowledged and addressed regarding the present study. The sample comprised active and healthy individuals as the authors understand that the tilt platform test could exacerbate pain and/or injury in individuals with ankle disorders. Additionally, the possibility of a control group being submitted to water immersion at room temperature or at rest should also be considered in order to ensure the effects of cold water immersion on ankle muscle activity. Further studies should include the analysis of the non-dominant lower limb that provides support during the tilting.

The results of this study indicate a decrease in the EMG response of the LG, TA, FL, RF, and GM muscles to ankle inversion after the use of cold water immersion in healthy male subjects, with a residual effect that lasts up to 30 minutes. Therefore, after cold water immersion of the ankle, special care should be taken with activities that require greater neuromuscular control.

\section{References}

1. Collins NC. Is ice right? Does cryotherapy improve outcome for acute soft tissue injury? Emerg Med J. 2008;25:65-8. http://dx.doi.org/10.1136/emj.2007.051664

2. Bleakley CM, Costello JT. Do Thermal Agents Affect Range of Movement and Mechanical Properties in Soft Tissues? A Systematic Review. Arch Phys Med Rehabil. 2013;94:149-63. http://dx.doi.org/10.1016/j. apmr.2012.07.023

3. Khanmohammadi R, Someh M, Ghafarinejad F. The effect of cryotherapy on the normal ankle joint position sense. Asian J Sports Med. 2011;2:91-8. http://journals.tums. ac.ir/abs.aspx?tums_id=18302

4. Algafly AA, George KP. The effect of cryotherapy on nerve conduction velocity, pain threshold and pain tolerance. $\mathrm{Br}$ J Sports Med. 2007;41:365-69. http://dx.doi.org/10.1136/ bjsm.2006.031237

5. Herrera E, Sandoval MC, Camargo DM, Salvini TF. Motor and sensory nerve conduction are affected differently by ice pack, ice massage, and cold water immersion. Phys Ther. 2010;90:581-91. http://dx.doi.org/10.2522/ ptj.20090131 
6. Bleakley CM, O'Connor S, Tully MA, Rocke LG, Macauley DC, Mcdonough SM. The PRICE study (Protection Rest Ice Compression Elevation): design of a randomised controlled trial comparing standard versus cryokinetic ice applications in the management of acute ankle sprain. BMC Musculoskelet Disord. 2007;19:12533. http://dx.doi.org/10.1186/1471-2474-8-125

7. Stacey DL, Gibala MJ, Ginis KAM, Timmnos BW. Effects of recovery method after exercise on performance, immune changes, and psychological outcomes. J Orthop Sports Phys Ther. 2010;40:656-65. http://dx.doi. org/10.2519/jospt.2010.3224

8. Bleakley CM, Costello JT, Glasgow PD. Should athletes return to sport after applying ice? A systematic review of the effect of local cooling on functional performance. Sports Med. 2012;42:69-87. http://dx.doi. org/10.2165/11595970-000000000-00000

9. Costello JT, Donnelly AE. Cryotherapy and joint position sense in healthy participants: a systematic review. J Athl Train. 2010;45:306-16. http://dx.doi. org/10.4085/1062-6050-45.3.306

10. Doeringer JR, Hoch MC, Krause BA. Ice application effects on peroneus longus and tibialis anterior motoneuron excitability in subjects with functional ankle instability. Int J Neurosci. 2010;120:17-22. http://dx.doi. org/10.3109/00207450903337713

11. Costello JT, Algar LA, Donnelly AE. Effects of wholebody cryotherapy $\left(-110^{\circ} \mathrm{C}\right)$ on proprioception and indices of muscle damage. Scand J Med Sci Sports. 2012;22:19098. http://dx.doi.org/10.1111/j.1600-0838.2011.01292.x

12. Rupp KA, Herman DC, Hertel J, Saliba SA. Intramuscular temperature changes during and after 2 different cryotherapy interventions in healthy individuals. J Orthop Sports Phys Ther. 2012;42:731-37. http://dx.doi. org/10.2519/jospt.2012.4200

13. Berg CL, Hart JM, Palmieri-Smith R, Cross KM, Ingersoll CD. Cryotherapy does not affect peroneal reaction following sudden inversion. J Sport Rehabil. 2007;16:28594. PMid: 18246895

14. Harriss DJ, Atkinson G. Update - Ethical standards in sport and exercise science research. Int J Sports Med. 2011;32:81921. http://dx.doi.org/10.1055/s-0031-1287829

15. Menacho MO, Pereira HM, Oliveira BIR, Chagas LMPM, Toyohara MT, Cardoso JR. The peroneus reaction time during sudden inversion test: Systematic review. J Electromyogr Kines. 2010;20:559-65. http://dx.doi. org/10.1016/j.jelekin.2009.11.007

16. Hatzel BM, Kaminski TW. The effects of ice immersion on concentric and eccentric muscle performance in the ankle. Isokinet Exerc Sci. 2000;8:103-7.
17. Kernozek TW, Greany JF, Anderson DR, Van Heel D, Youngdahl RL, Benesh BG. The effect of immersion cryotherapy on medial-lateral postural sway variability in individuals with a lateral ankle sprain. Physiother Res Int. 2008;13:107-18. http://dx.doi.org/10.1002/pri.393

18. Felici F. Neuromuscular responses to exercise investigated through surface EMG. J Electromyogr Kinesiol. 2006;16:578-85. http://dx.doi.org/10.1016/j. jelekin.2006.08.002

19. Murley GS, Menz HB, Landorf KB, Bird AR. Reliability of lower limb electromyography during overground walking: a comparison of maximal- and sub-maximal normalisation techniques. J Biomech. 2010;43:749-56. PMID 19909958. http://dx.doi.org/10.1016/j.jbiomech.2009.10.014

20. Wolf SL, Basmajian JV. Intramuscular temperature changes deep to localized cutaneous cold stimulation. Phys Ther. 1973;53:1284-88. PMID: 4759710

21. Cordova ML, Bernard LW, Au KK, Demchak TJ, Stone MB, Sefton JM. Cryotherapy and ankle bracing effects on peroneus longus response during sudden inversion. J Electromyogr Kines. 2010;20:348-53. http://dx.doi. org/10.1016/j.jelekin.2009.03.012

22. Herrera E, Sandoval MC, Camargo DM, Salvini TF. Effect of walking and resting after three cryotherapy modalities on the recovery of sensory and motor nerve conduction velocity in healthy subjects. Rev Bras Fisioter. 2011;15:233-40. http://dx.doi.org/10.1590/ S1413-35552011000300010

23. Luzzati V, Mateu L, Marquez G, Borgo M. Strutural and electrophysiological effects of local anesthetics and of low temperature on myelinated nerves: implication of the lipid chains in nerve excitability. J Mol Biol. 1999;286:13891402. http://dx.doi.org/10.1006/jmbi.1998.2587

24. Uchio Y, Ochi M, Fujihara A, Adachi N, Iwasa J, Sakai Y. Cryotherapy influences joint laxity and position sense of the healthy knee joint. Arch Phys Med Rehab. 2003;84:13135. http://dx.doi.org/10.1053/apmr.2003.50074

\section{Correspondence}

\section{Rinaldo Roberto de Jesus Guirro}

Universidade de São Paulo

Faculdade de Medicina de Ribeirão Preto

Av. Bandeirantes, 3900, Monte Alegre

CEP 14049-900, Ribeirão Preto, SP, Brazil

e-mail: rguirro@fmrp.usp.br 